\title{
El Sumak Kawsay desde la perspectiva del sistema jurídico ecuatoriano
}

\section{The Sumak Kawsay from the perspective of the Ecuadorian legal system}

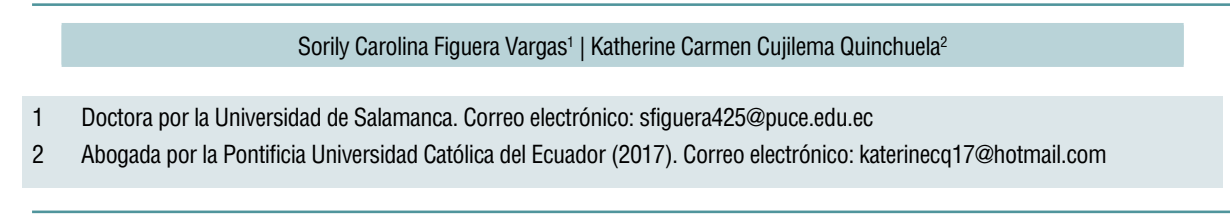

\section{RESUMEN}

La Constitución del Ecuador de 2008 incorporó la acepción Sumak Kawsay o "Buen Vivir" en su preámbulo y artículo 14, lo cual representó un cambio de paradigma que incluyó y consolidó la visión ancestral en el sistema legal ecuatoriano, para la consecución de un desarrollo sostenible. En este artículo se realizará una reflexión sobre el Sumak Kawsay, su regulación legislativa y cuál pretende ser su alcance. Asimismo, siguiendo un método de investigación jurisprudencial, se establecerá cómo la Corte Constitucional del Ecuador, como máximo intérprete de la Carta Magna, ha interpretado el significado del Sumak Kawsay.

Palabras clave: Buen vivir, Corte Constitucional del Ecuador, sistema jurídico ecuatoriano y Sumak Kawsay.

\section{ABSTRACT}

The Constitution of Ecuador of 2008 incorporated the meaning Sumak Kawsay or "Good Living" in its preamble and article 14, which represented a paradigm shift that incorporated and consolidated the ancestral vision in the Ecuadorian legal system for the achievement of sustainable development. This article will reflect on the Sumak Kawsay, its legislative regulation and what it intends to be its scope. Also, following a method of jurisprudential research, it will be established how the Constitutional Court of Ecuador, as interpreter of the Constitution, has interpreted the meaning of Sumak Kawsay.

Keywords: Good living, Constitutional Court of Ecuador, Ecuadorian legal system and Sumak Kawsay.

\section{JUSTICIA}

Recibido: 16-08-17 Aceptado: $16-09-17$ Publicado: 18-01-18

DOI: https://doi.org/10.17081/ust.23.33.2882 


\section{INTRODUCCIÓN}

El Sumak Kawsay, desde la visión constitucional ecuatoriana, corrobora el cambio de paradigma mediante la inserción de un enfoque ancestral. En inicio, ratifica el pensamiento en conjunto, es decir, suprime todo tipo de individualismo; por lo tanto, este estudio parte del pilar del respeto que crea un vínculo de armonía con la naturaleza y fortalece las relaciones con responsabilidad entre los seres humanos, considerando que todos pertenecen a un mismo conjunto. A partir de esta construcción se crean los cimientos de una verdadera metamorfosis, un cambio que ha envuelto a Ecuador a partir de una nueva forma de vida que ha sido plasmada con sencillez, porque su enfoque se dirige a no acumular riquezas sino a compartir con la comunidad, pues lo más importante es el nexo que se crea entre todos. En la misma línea conceptual:

El Sumak Kawsay puede ser definido como [una] forma de vida en armonía con la naturaleza y con otros seres humanos. Esta es la idea que está implícita en las citadas constituciones. Idea que parte de una concepción de la vida deseable inspirada en la cultura de los pueblos indígenas, quechuas y aymaras especialmente, y que se apoya en los principios de equidad social y sostenibilidad ambiental (Hidalgo \& Cubillo, 2014, p. 26).

Asimismo, "la Constitución del Ecuador (2008) y la Constitución Política del Estado de Bolivia (2009) [lo] traducen, respectivamente, por 'buen vivir' y 'vivir bien"' (Hidalgo \& Cubillo, 2014, p. 3). En Suramérica, el Estado Pluricultural de Bolivia incorporó en su Constitución el término en aymara-quechua suma qamaña, traducido como "vivir bien". Por su parte, Ecuador en la Constitución de 2008 marca una de las pautas a que hace hincapié la inclusión del término kichwa Sumak Kawsay, "Buen Vivir".

A partir de la vigencia de la actual Constitución de la República del Ecuador ${ }^{3}$, la cual entre sus múltiples innovaciones dentro de ese sistema jurídico, determina en su artículo 1, que "El Ecuador es un Estado constitucional de derechos y justicia, social, democrático, soberano, independiente, unitario, intercultural, plurinacional" (Constitución del Ecuador, 2008, Art.1), quedando implícito el reconocimiento expreso de una diversidad de culturas que confluyen en el país.

Una razón tangible es la visión intercultural que engloba el Sumak Kawsay, que ha sido incluida en la Constitución de la República del Ecuador de

3 Registro Oficial $N^{\circ} 449$ de 20 de octubre de 2008. 
2008, centrándose profundamente en el ser humano con la conectividad de la historia ancestral que forma parte de la cultura de los ecuatorianos y es imprescindible para entablar relaciones con las actividades cotidianas de la sociedad. En el decurso de este estudio se esbozará una aproximación a la traducción literal en español del Sumak Kawsay, así como, se realizará un análisis desde el marco constitucional y se presentará un estudio desde la jurisprudencia constitucional ecuatoriana y del Plan Nacional del "Buen Vivir" 2017-2021, 2013-2017 y 2009-2013. De igual manera, se establecerán las características del "Buen Vivir".

\section{APROXIMACIÓN DE LA ACEPCIÓN Y DEFINICIÓN DEL SUMAK KAWSAY}

Cabe tener en cuenta que el "Buen Vivir" es una forma de compaginación de la cosmovisión indígena con esta realidad, que se proyecta en la construcción de una nueva percepción de la vida que se remite a la cultura de los ancestros, quienes han sido pioneros en conservar sus raíces; estas son preservadas en la actualidad a pesar del tiempo porque son la base de una práctica que continúa replicándose. Por consiguiente, la construcción de las ideas de Buen Vivir en sus formulaciones recientes, pueden rastrearse por lo menos [desde] la década de 1990, cobrando fuerte impulso a inicios de los años 2000 (Gudynas, 2014). Se debe indicar que "el Sumak Kawsay en su traducción literal desde el kichwa significa buena vida o bien vivir. Este concepto proviene y se sintoniza con las culturas indígenas andinas de América del Sur y es acogido por el Ecuador como el 'Buen Vivir”' (Quirola, 2009, p. 22).

Desde el punto de vista de la acepción literal en español el concepto del "Buen Vivir" se dirá que forma parte del marco constitucional en Ecuador, lo cual se debe a la influencia ancestral de una forma de vida diferente a la habitual. El Sumak Kawsay es una forma de vida, plena, equilibrada, sana, armónica y modesta, en los planos individual y social. Es un sistema de vida consciente que mantiene y cultiva relaciones de equilibrio y armonía con la naturaleza que le permite al ser humano alcanzar una existencia en plenitud (Maldonado, 2010).

El Sumak kawsay o 'Buen vivir' se define como vida armónica, en tal perspectiva, todo esfuerzo humano debe procurar e implementar las condiciones materiales y espirituales para edificar y conservar una vida armónica (Wray, 2009). De la misma manera, este concepto contiene la aspiración de la inclusión de una vida en la cual prime la armonía. Así pues, como un aporte dentro del Estado Pluricultural de Bolivia, se precisa la significación que engloba la visión de los antepasados para entablar una relación de equilibrio, 
porque cada uno de sus integrantes es parte de un mismo entorno. Además, se subraya que el vocablo aymara "suma qamaña" es traducido como "vivir bien" o "vivir en plenitud" (Huanacuni, 2010).

Es preciso indicar la proyección de la visión en armonía con todos los seres de la naturaleza, sean bióticos o abióticos, por converger en un mismo hábitat en el cual ineludiblemente existe un punto de equilibrio. Generalmente, su origen es parte de la identidad cultural, la cual mantuvo que la tierra es la madre de lo creado en donde habitamos; porque siendo conocedores de la historia, se insta a remitirnos a aquella particular calidad de vida que anhela el "Buen Vivir" para desarrollar la valoración humanista con la concatenación de vivir en paz con la naturaleza.

De forma precisa, se apunta que el Sumak Kawsay (buen vivir o vida digna), concreta toda la cosmogonía comunitaria de origen indígena que se intenta proyectar, a nivel de Estado, en todo un sistema social y jurídico de derechos y sociabilidad; y que se refleja en los últimos proyectos constitucionales del continente americano de este siglo XXI (Palacios, 2008). A partir de allí, claramente se define la instrumentalización de la organización política y de los dispositivos jurídicos para garantizar los intereses y el logro de los proyectos de vida de los seres humanos, de los grupos y de la naturaleza. Se trata así, de las exigencias para alcanzar el 'Buen Vivir' o Sumak Kawsay que prevé la Constitución del Ecuador (Wilhelmi, 2008).

Entonces, el Sumak Kawsay o "Buen Vivir” es un conjunto de varias aristas en las cuales se aúnan dos vertientes imprescindibles que es la concienciación acerca de la cosmovisión de vida, la cual se complementa con la óptica de cohabitar con respeto a la naturaleza para incentivar el trabajo en comunidad que deja atrás todo tipo de individualismo. De esta manera, se proyecta un equilibrio mancomunado en el que es trascendental que se resguarde el eje de responsabilidad porque todos somos parte del mismo rompecabezas de la vida.

El "Buen Vivir" está incorporado en el marco constitucional ecuatoriano a partir del 2008 como un concepto innovador que lucha inalcanzablemente por los derechos, sobre todo por la justicia y la igualdad. Este cambio de cosmovisión que se remite a la forma de vida ancestral, la cual no requiere de un gran amontonamiento de riquezas sino de lo suficiente para vivir modestamente, pero pensando en los demás, parte del punto de que el panorama en 
comunidad toma más fortaleza porque los seres humanos, al pertenecer a la madre tierra, son parte de un solo grupo que habita junto con la naturaleza. Bajo esta concienciación, que vuelve al ser humano responsable de todas las actividades que desempeña, se mantiene la idea de salvaguardar el hábitat del cual formamos parte. Además, la obligatoriedad de la Carta Magna reitera en su contenido la consecución de que todos somos parte de una sola comunidad para la realización de un todo que se encuentra en el Sumak Kawsay.

\section{MARCO CONSTITUCIONAL}

El preámbulo de la Constitución de la República del Ecuador de 2008 destaca la decisión de cimentar una novedosa forma de convivencia ciudadana, en diversidad y armonía con la naturaleza, para lograr el Buen Vivir; es decir, el Sumak Kawsay. En el segundo Título sobre Derechos, Capítulo Segundo, Derechos del Buen Vivir, se encuentra en la Sección Primera: Agua y alimentación (Arts. 12 y 13); Sección Segunda: Ambiente sano (Arts. 14 y 15); Sección Tercera: Comunicación e información (Arts. 16 al 20); Sección Cuarta: Cultura y ciencia (Arts. 21 al 25); Sección Quinta: Educación (Arts. 26 al 29); Sección Sexta: Hábitat y vivienda (Arts. 30 y 31); Sección Séptima: Salud (Art. 32); y Sección Octava: Trabajo y seguridad social (Art. 33 y 34). Además, el Título VI, Régimen de Desarrollo, Capítulo Primero, Principios generales, tiene el enfoque hacia la realización del Buen Vivir (Arts. 275 al 278).

Es así como, el parágrafo tercero del artículo 275 prevé que el buen vivir exigirá que las personas, comunidades, pueblos y nacionalidades eficazmente disfruten de sus prerrogativas, y puedan ejercer responsabilidades en el contexto de la interculturalidad, respetando la diversidad y el convivir conforme a la naturaleza (Constitución del Ecuador, 2008, Art. 275).

A partir de la redacción constitucional, el "Buen Vivir" involucra a todos para convivir en armonía con la naturaleza porque en Ecuador confluye la interculturalidad por la presencia de las diversas culturas que forman parte de nuestro país. En concordancia con el artículo constitucional citado anteriormente, el artículo 14 de la Constitución de Montecristi señala que "se reconoce el derecho de la población a vivir en un ambiente sano y ecológicamente equilibrado, que garantice la sostenibilidad y el buen vivir, Sumak Kawsay" (Constitución del Ecuador, 2008, Art. 14).

Cabe sintetizar que el Buen Vivir, más que una declaración constitucional, significa una oportunidad para construir colectivamente una nueva forma de 
organización de la vida misma (Acosta, 2009). El mandato constitucional, más allá de ser de carácter obligatorio para la sociedad ecuatoriana, también forma parte de este cambio de visión. Además, agrupa un punto indispensable que es la colectividad, porque no se trata de marcar un individualismo sino de crear un marco en común; es decir, una organización de vida en la cual seamos partícipes de la edificación de este cambio de paradigma. Es congruente el aporte a esta nueva estructura conjuntamente integrada por todos.

Es importante, además, indicar que uno de los principales factores corresponde a no cerrarse en un concepto de banal importancia, sino que implica adoptar un nuevo horizonte que se mantiene en todo el contenido de la Carta Magna ecuatoriana. En este planteamiento es indispensable establecer un parámetro esencial que, manifiesta la necesidad de un salto cualitativo para alcanzar una Constitución holística, completa, que responde a los altos estándares que exige la actualidad y los desafíos de cambio (León, 2010).

Hoy por hoy, el rango constitucional del que forma parte el "Buen Vivir" tiene un asidero posicionamiento en el conjunto de todos los cuatrocientos cuarenta y cuatro artículos que la contienen. No se reduce a ser una simple anotación superflua, sino que abarca un compromiso de carácter obligatorio frente a un nuevo desafío de transformaciones que pretende concienciar a todos agrupadamente. Por ende, el Sumak Kawsay involucra una visión holística de la vida, se manifiesta a través de elementos básicos que el ser humano ha identificado para su coexistencia, cuya funcionalidad se caracteriza en la corresponsabilidad energética hombre-naturaleza, en la comprensión del mundo circundante, en la conciencia del tiempo y los espacios de la vida (Calapucha, 2012, p. 26).

El concepto del "Buen Vivir" constituye la metamorfosis de una lucha por un equilibrio social con una visión ancestral, esto es debido a la incorporación en el marco constitucional. El "Buen Vivir" busca la aplicación de condiciones de vida necesarias para que prime el respeto profundo por los derechos humanos rompiendo las cadenas del capitalismo, dando paso al socialismo del "Buen vivir". En particular, es importante que se consolide la base firme del Sumak Kawsay que está en la convivencia con ciertas necesidades básicas que son mínimas para todos los seres humanos.

Entonces, [E] Buen Vivir se fundamenta en una ética de lo suficiente para toda la comunidad, y no solamente para el individuo. Su preocupación central 
no es acumular para luego vivir mejor (Acosta, 2009). Un aspecto fundamental es suprimir el individualismo tan marcado propiciado en el transcurso de la época, la cual será reemplazada por el bienestar en comunidad de todas las personas que anhelan una convivencia más profunda y sustancial en el vivir, porque no guarda sentido alguno aglomerar para posteriormente vivir de una forma mejor. Un punto en consideración es el pensamiento de vida en comunidad para la autorrealización de toda la comunidad. Así pues, los principales pilares para concretar el "Buen Vivir" se fijan en la actual Constitución del Ecuador y se pueden sistematizar en tres temas fundamentales: la estructura económica, los derechos de la naturaleza y los derechos de los seres humanos (Larrea, 2014).

El desarrollo del "Buen Vivir" es una respuesta a los constantes cambios que mantienen la incorporación de esta base congruente con estas condiciones de vida. Este estudio hace hincapié en que "(...) es muy importante saber por dónde se camina, con qué se camina, y con quiénes se camina. Esto quiere decir que no hay camino que nos lleve al Sumak Kawsay sino que el Sumak Kawsay es el camino" (Oviendo, 2016, p. 25).

Indubitablemente, es la edificación de una visión ancestral que se incorpora en el mandato constitucional como de carácter obligatorio y como parte de un cambio de paradigma, porque lo más importante es la persona y la responsabilidad en conjunto, mas no únicamente la forma individual, es la prevalencia principal que se cristaliza a partir de la cosmovisión indígena. En definitiva, el compromiso inexcusable de colaboración es tarea de todos, la Carta Magna reafirma esta exigencia de una transformación social por la lucha de los derechos, pero, sobre todo, para lograr el equilibrio que requiere la armonización con el entorno en el cual habitamos. Los derechos del "Buen Vivir" son un conjunto de condiciones indispensables para el desarrollo de la vida, a partir del preámbulo que da orientación al Sumak Kawsay.

\section{PLANES NACIONALES DEL BUEN VIVIR}

\section{Plan nacional del buen vivir 2009-2013}

Este Plan estaba formado por doce objetivos nacionales para el Buen Vivir que se ha trazado cada uno con sus políticas y sus metas para garantizar la igualdad, mejorar la calidad de vida de los habitantes, los derechos de la naturaleza y construir un país democrático que dinamice nuestra identidad porque:

El pensamiento ancestral es eminentemente colectivo. La concepción 
del Buen Vivir necesariamente recurre a la idea del «nosotros» porque el mundo no puede ser entendido desde la perspectiva del «yo» de Occidente. La comunidad cobija, protege, demanda y es parte del nosotros. La comunidad es el sustento y es la base de la reproducción de ese sujeto colectivo que todos y cada uno «somos». (Plan Nacional para el Buen Vivir, 2009, p. 12)

En su orden, los objetivos hacen referencia a: Objetivo primero: Auspiciar la igualdad, cohesión e integración social y territorial en la diversidad. Objetivo segundo: Mejorar las capacidades y potencialidades de la ciudadanía. Objetivo tercero: Mejorar la calidad de vida de la población. Objetivo cuarto: Garantizar los derechos de la naturaleza y promover un ambiente sano y sustentable. Objetivo quinto: Garantizar la soberanía y la paz e impulsar la inserción estratégica en el mundo y la integración latinoamericana. Objetivo sexto: Garantizar el trabajo estable, justo y digno en su diversidad de formas. Objetivo séptimo: Construir y fortalecer espacios públicos, interculturales y de encuentro común. Objetivo octavo: Afirmar y fortalecer la identidad nacional, las identidades diversas, la plurinacionalidad y la interculturalidad. Objetivo noveno: Garantizar la vigencia de los derechos y la justicia. Objetivo décimo: Garantizar el acceso a la participación pública y política. Objetivo undécimo: Establecer un sistema económico social, solidario y sostenible. Objetivo duodécimo: Construir un Estado democrático para el Buen Vivir.

\section{Plan nacional del buen vivir 2013-2017}

Este Plan es el camino de planificación trazado para efectivizar las pautas que se han plasmado en los objetivos antes descritos, que serán las guías necesarias para su cumplimiento. A partir de la visión del presente con la proyección a futuro como aporte hacia un cambio significativo para la sociedad ecuatoriana, es preciso indicar que es de carácter obligatorio orientar la forma en la cual se cumplirá con varias directrices que son un conjunto de objetivos encaminados a buscar la igualdad cultivando la identidad nacional, bajo el respeto de derechos que están plasmados para que efectivicen la obligatoriedad de este cambio de paradigma en el país.

El Plan señala que la dimensión de centro está encaminada hacia esta particular forma de vida en sociedad porque "el Buen Vivir es nuestro horizonte; ofrece alternativas para construir una sociedad más justa, en la que el centro de la acción pública sea el ser humano y la vida. Supera los límites de las visiones convencionales de desarrollo que lo conciben como un proceso 
lineal, de etapas históricas sucesivas, que reducen el concepto a una noción exclusiva de crecimiento económico" (Plan Nacional para el Buen Vivir, 2013, p. 40).

El Plan Nacional del Buen Vivir 2013-2017 señala, en relación a la sociedad solidaria: "la comunidad de acción está en el corazón de los proyectos democrático-republicanos. Parte del siguiente postulado humanista: 'Yo te doy porque tú necesitas y no porque pueda obtener un beneficio a cambio" (Plan Nacional para el Buen Vivir, 2013). El Plan está formado por doce objetivos. Objetivo primero: Consolidar el Estado democrático y la construcción del poder popular. Objetivo segundo: Auspiciar la igualdad, la cohesión, la inclusión y la equidad social. Objetivo tercero: Mejorar la calidad de vida de la población. Objetivo cuarto: Fortalecer las capacidades y potencialidades de la ciudadanía. Objetivo quinto: Construir espacios de encuentro común y fortalecer la identidad nacional, las identidades diversas, la plurinacionalidad y la interculturalidad. Objetivo sexto: Consolidar la transformación de la justicia y fortalecer la seguridad integral, en estricto respeto a los derechos humanos. Objetivo séptimo: Garantizar los derechos de la naturaleza y promover la sostenibilidad ambiental territorial y global. Objetivo octavo: Consolidar el sistema económico social y solidario, de forma sostenible. Objetivo noveno: Garantizar el trabajo digno en todas sus formas. Objetivo décimo: Impulsar la transformación de la matriz productiva. Objetivo undécimo: Asegurar la soberanía y eficiencia de los sectores estratégicos para la transformación industrial y tecnológica. Objetivo duodécimo: Garantizar la soberanía y la paz, profundizar la inserción estratégica en el mundo y la integración latinoamericana.

De la comparación de ambos Planes Nacionales para el Buen Vivir, el Plan de 2013-2017 tiene grandes diferencias respecto del anterior, así como tiene un cierto símil con varios objetivos y varias diferenciaciones, a la vez que también nuevos objetivos que han sido abarcados. No obstante, todos los objetivos que se plantean tienen un único horizonte: el socialismo del Buen Vivir de todos.

Concomitantemente, se requiere de la colaboración de todos quienes habitamos en el país, porque el aunar fuerzas entre todos será un buen inicio para que en la sociedad ecuatoriana únicamente prevalezca el pensar en los demás y no un sesgo que suprima esta trasformación ya que:

El Buen Vivir no puede sustentarse sino en una ciudadanía activa, sujeto de una gran soberanía del conocimiento, con las oportunidades para desarrollar capacidades y emprender acciones, todo ello en 
armonía con la naturaleza que ahora es sujeto de derechos, y configurar un sistema de inclusión y equidad, y de respeto a la biodiversidad. (Quintero, 2009, p. 35)

Es importante que en este aspecto el avance del país no se detenga. Que predomine esta calidad de vida en armonía con nuestro entorno y con la de los demás sería un compromiso de todos.

\section{Plan nacional del buen vivir 2017-2021}

Con un cambio de gobierno en el Ecuador, luego de diez años de continuidad, en el año 2017 se presentó el Plan Nacional del Buen Vivir. El Plan Nacional de Desarrollo 2017-2021 señala que dará continuidad a las mismas líneas de las ediciones que le precedieron, con base en la llamada década ganada, desatacando las metas y evolución lograda en dicho periodo como resultado del desarrollo sostenible.

No obstante, en el nuevo plan se deja en claro la existencia de otros retos que se deben superar. Así pues, los mencionados desafíos son enmarcados en torno a tres ejes principales: "derechos para todos durante toda la vida, economía al servicio de la sociedad y capacidades sociales y estatales para contar con un tejido social más fuerte y un Estado democrático para el bien común" (Plan Nacional para el Buen Vivir, 2017).

En este plan se considera que la meta está en constituir una economía de inclusión con elevado valor agregado y una sociedad con renovados valores, fundamentados en la solidaridad y la corresponsabilidad. Será necesario entonces, esperar los resultados de esta visión que apenas se implementa al momento de rectar esta disertación.

\section{JURISPRUDENCIA CONSTITUCIONAL SOBRE EL SUMAK KAWSAY}

Aplicando un método de investigación jurisprudencial, se estudiarán algunas sentencias emitidas por la Corte Constitucional del Ecuador, las cuales han desarrollado sucintamente la concepción del Sumak Kawsay. El Dictamen $\mathrm{N}^{\circ}$ 0006-09-DTI-CC de la Corte Constitucional del Ecuador, de 14 de mayo de 2009, resolvió la consulta de constitucionalidad presentada por el presidente Rafael Correa, sobre la "Convención Internacional para la Protección de todas las Personas contra las Desapariciones Forzadas." Allí por primera vez se hizo mención al Sumak Kawsay en el marco de la Constitución de 2008, citando a Marco Aparicio Wilhelmi, se estableció que: 
La traducción del Sumak Kawsay kichwa, que constata la presencia de las aportaciones de las culturas indígenas en la construcción de un proyecto de desarrollo social centrado en una mejora de las condiciones de vida, no se debe medir en términos cuantitativos sino cualitativos. (Corte Constitucional del Ecuador, Caso Nº004-09-TI, 2009).

Luego, la Sentencia N ${ }^{\circ}$ 0006-10-SEE-CC, de 25 de marzo de 2010, sobre la declaratoria de Estado de Excepción en relación con los niveles alarmantes de contaminación ocasionados en la laguna de Yahuarcocha, ubicada en la ciudad de Ibarra, provincia de Imbabura, con el objetivo de protegerla. El fallo al referirse al derecho de la población a vivir en un ambiente sano y al Sumak Kawsay, recalca que

El Sumak Kawsay (buen-vivir) es parte de la estructura del Estado, sobre el cual se asienta el proyecto de Estado que conduce a la sociedad ecuatoriana a un buen vivir. Basa su fundamento en mantener un equilibrio entre el ser humano, los recursos naturales y el desarrollo, en un marco de racionabilidad y equilibrio; para tal efecto, el Estado garantiza a sus habitantes el acceso a los derechos constitucionales y, en especial, constituye el marco de los derechos económicos, sociales y culturales, como son: el ambiente, la salud, la educación, el desarrollo, etc., no solo como mera enunciación declarativa, sino como todo un andamiaje conducente a que los mismos se viabilicen. (Corte Constitucional del Ecuador, Caso Nº008-09-EE, 2010)

En definitiva, dentro de su contenido, ambas sentencias no tienen como centro el aporte de una definición general del "Buen Vivir", pero hacen una pausa para analizar su fundamento y concebirla como una verdadera forma de vida. En este orden de ideas, este estudio resalta cómo el Estado garantiza el cumplimiento de los derechos constitucionales. El "Buen Vivir" bien entendido, busca mejorar la vida de todos los habitantes, esta puede ser sencilla, pero en comunidad, fortaleciendo lazos de ayuda unos con otros porque esto forma parte de un proyecto de desarrollo social que involucra la participación de todos.

La Sentencia N ${ }^{\circ} 166-15-S E P-C C$ de la Corte Constitucional del Ecuador, de 20 de mayo de 2015 , determinó que:

El sumak kawsay constituye un fin primordial del Estado, donde esta nueva concepción juega un papel trascendental en tanto promueve 
un desarrollo social y económico en armonía con la naturaleza. Es así que la importancia de la naturaleza dentro de este nuevo modelo de desarrollo se ve plasmada en el artículo 10 de la Constitución de la República que consagra: "Las personas, comunidades, pueblos, nacionalidades y colectivos son titulares y gozarán de los derechos garantizados en la Constitución y en los instrumentos internacionales. La naturaleza será sujeto de aquellos derechos que le reconozca la Constitución.'Así, el Ecuador se convierte en el primer país en reconocer y amparar constitucionalmente los derechos de la naturaleza. (Corte Constitucional del Ecuador, Caso Nº507-12-EP, 2015)

En el fallo antes citado el máximo tribunal constitucional del Ecuador fue más allá y, específicamente, determinó que el Sumak Kawsay es un objetivo fundamental del Estado ecuatoriano, considerando el término como una novedosa concepción que tiene un rol trascendental, al promocionar el desarrollo social y económico, esto en consonancia con la naturaleza.

\section{CARACTERÍSTICAS DEL SUMAK KAWSAY}

\section{PRIORIDAD DE LA NATURALEZA EN EQUILIBRIO Y ARMONÍA}

Un punto trascendental en las características del Sumak Kawsay es el equilibrio y armonía con la madre tierra, porque da prioridad a la naturaleza antes que al ser humano (Maldonado, 2013). En primer lugar, hay que tener presente que "uno de los principales fundamentos del Sumak Kawsay descansa en la armonía de los procesos humanos con la naturaleza, a la cual desde la perspectiva cultural indígena-originaria se la denomina la Pacha Mama" (García, 2016, p. 20). Debido al raciocinio ancestral que guarda un verdadero respeto en relación con la naturaleza, es necesario que inste por mantener cierta armonía en la cual habitamos las personas. Ineludiblemente, se mantiene el cuidado adecuado por convivir en un solo lugar para que los seres humanos seamos fieles a una cooperación en pos de mantener la prioridad de precautelar el único lugar que comparte con nosotros todo a su alrededor. Por consiguiente, la visión de Sumak Kawsay mantiene un epicentro de preferencia a la naturaleza en primer lugar y al ser humano a continuación.

A partir del preámbulo de la Constitución de la República del Ecuador que prevé "CELEBRANDO a la naturaleza, la Pacha Mama, de la que somos parte y que es vital para nuestra existencia". El Título II, Derechos, Capítulo Primero, señala en el artículo 10 en la parte pertinente, que "La naturaleza será sujeto de aquellos derechos que le reconozca la Constitución.' En el Título 
II, Derechos, Capítulo Séptimo, se contemplan los Derechos de la Naturaleza (Arts. 71 al 74).

Para propiciar esta articulación hay que tener presente que la naturaleza goza de derechos y se le debe un respeto íntegro, conforme lo señala la redacción legal de la Carta Magna, porque la Pacha Mama brinda a todas las personas la oportunidad de continuar a su cuidado por la preponderancia que mantiene con todo nuestro entorno. Cabe indicar que los seres humanos habitamos en un lugar acogido y no podemos sobrepasar los límites de respeto a la naturaleza. El entorno que tienen es una manifestación de vida, y ante ello se vuelve irrisorio la cantidad de dinero que posea una persona, o pensar en la preeminencia del ser humano sin contemplar lo que nos brinda la naturaleza. Como seres humanos conscientes del detrimento que padece el planeta, somos los llamados a cambiar este panorama para que nada empañe el respeto a la tierra. Lo realmente supremo es la esencia de la vida junto con la naturaleza, y nosotros somos los encargados de cuidarla y conservar el objetivo de protegerla para ayudar al planeta, pues significativamente somos parte del mismo lugar.

\section{UNA COSMOVISIÓN EN ESENCIA COMUNITARIA}

El individualismo no tiene cabida en el Sumak Kawsay porque esta visión de la vida reúne la participación en comunidad de las personas que pertenecemos a esta. Es indispensable que pensemos en otras personas y mantengamos ese ícono de ayudarnos entre nosotros porque somos seres humanos. Por ende, el bienestar de otras personas tanto como el mío es fundamental, y es menester que para ello se antepongan los principios y objetivos del Sumak Kawsay a fin de evitar todo tipo de parcialización, porque “(...) el tema central es la recuperación de la vida en comunidad” (Larrea, 2014, p. 3). El pensamiento en comunidad es de vital importancia porque no se piensa únicamente en 'mi' porvenir sino en el del otro, y se contempla la posibilidad de ayuda hacia los demás no por tener un beneficio sino únicamente por cooperación. Solo cuando se percibe esta colaboración es cuando en realidad se sienten los cambios.

Cabe recalcar que, para las naciones aymara-quechua (Bolivia) y kichwa (Ecuador) todo tiene dos orígenes: Pacha Kama o Pachatata (padre cosmos, energía o fuerza cósmica) y Pacha Mama (Madre Tierra, energía o fuerza telúrica), las cuales producen todas las formas necesarias para existencia (Huanacuni, 2010).

Las fuentes tanto Pacha Kama como Pacha Mama son padre y madre que 
originaron la vida, por lo que todo proviene de ellos. Más aún, desde la visión ancestral aquellos padres son los coautores de nuestra existencia y a diario se manifiestan en nuestro entorno, desde ellos emana la vida y por lo tanto, su protección es una de las misiones pioneras. El Buen Vivir impulsa a construir lo comunitario y lo social, frente a las visiones fragmentarias, economicistas

y mercadotécnicas del desarrollo. Se nutre de lo mejor del pensamiento del mundo porque ha sido un anhelo de la humanidad, no solamente durante siglos, sino durante milenios, miles de años atrás (Larrea, 2014).

En la actualidad, por la vertiginosidad del tiempo y las diversas actividades que ahora ocupan a la humanidad, las personas se han desarraigado de sus orígenes y han perdido la capacidad de ver más allá y pensar en comunidad; sin embargo, siempre será el momento de volver al ejemplo de aquellas personas que con sabiduría marcaron el inicio de los tiempos, con una visión de comunidad, una visión que congregaba a cada ser humano con su individualidad a formar parte de un todo, ese todo que hoy se traduce en la cosmovisión de Sumak Kawsay.

\section{LA IMPORTANCIA DEL CULTIVO DE LAS RELACIONES}

Asimismo, surge la relación con la naturaleza como parte de un solo entorno, el cual también lo conformamos. "Se sustituye el derecho de propiedad de la tierra por el derecho de 'Relación' con ella” (Maldonado, 2013, p. 26). El enfoque es esta relación que se mantiene como fusión de los seres humanos con la naturaleza porque la visión no es adueñarse de una parte de la tierra sino convivir con ella en armonía.

La forma de vida en comunidad es el principal punto de enfoque para la existencia en armonía, y mediante ella se formula una relación con la tierra como parte de un solo pensamiento que se evidencia en vivir naturalmente con nuestro ambiente. Es decir, la vida creando correlaciones, entre humanos y entorno natural, buscando una convivencia libre y voluntaria en el marco de la fusión hombre-naturaleza, pero bajo el compromiso de fomentar relaciones para convivir mejor.

Adicionalmente, "nosotros no somos dueños de la tierra, nosotros pertenecemos a ella. Entonces, más que reclamar un derecho de propiedad, lo que pedimos es el ‘Derecho de Relación' con la Madre Tierra” (Huanacuni, 2010, p. 12). Una vez que hagamos nuestro ese sentido de vida en comunión con la naturaleza, cabría establecer relaciones que nos mantengan unidos, en 
una fusión, como uno solo, surge entonces la idea de interiorizar la vida en comunidad para que sea avizorada en una relación que requiere una gran labor al momento de estrechar un vínculo con nuestra madre tierra que nos ha enriquecido con todo lo que nos rodea. El reto es formar parte de una cadena de unión que piensa en los demás, que no acumula riqueza como concepto falso de "Buen Vivir", sino que es la conexión con la naturaleza, el paso inequívoco para continuar fortaleciendo relaciones hombre-naturaleza como sinónimo de vida.

Alrededor de esta protección constitucional que forma parte de un cambio en el consumo natural de la naturaleza en calidad de sujeto de derechos, el resguardar esta relación en la que se avizora que todos formamos parte de un mismo entorno en el cual vivimos siendo parte de este ambiente, se inicia por el pensamiento dominante se vive en conjunto de parte de un todo. Particularmente, de lo anotado surge que todos somos parte del mismo entorno, entonces hasta qué punto se limita el utilizar los bienes de la naturaleza de forma indiscriminada.

\section{RESPONSABILIDAD CON UNO MISMO}

En el mundo occidental se promocionan los derechos y las obligaciones. Al contrario, en los pueblos indígenas autóctonos la vida transcurre en responsabilidad desde la complementación y la reciprocidad (Huanacuni, 2010). Evidentemente, todo acto de compromiso se resume en que constantemente esta visión requiere de una total convicción de cada una de las personas, porque nace y se mantiene con uno mismo.

Es necesario argumentar que la responsabilidad la mantiene cada una de las personas porque forma parte de su naturaleza vivir de esta manera, en la cual la complementación se encuentra presente y es lo que tenemos en nuestros días, y nosotros somos permanentemente precursores de este nexo de responsabilidad con nuestro entorno.

La visión del Sumak Kawsay es una plataforma que cuestiona la realidad que atravesamos porque es cuestión de un profundo compromiso de todos los ecuatorianos, y además de ser un mandato constitucional, rescata una práctica de nuestros ancestros que pone en consideración la forma de vida indígena como sus creencias, que han perdurado a pesar del paso del tiempo. Además, nuestra Carta Magna suma a su contenido la incorporación de esta visión de vida que nos deja tantas lecciones que son el espejo de esta práctica de responsabilidad con todas las personas porque esta se inicia con cada uno 
de nosotros.

Por lo tanto, el "Buen Vivir" es una conquista de convivencia de los seres humanos con la naturaleza porque se aplican las condiciones de una vida más justa, en la que se respeten los derechos de los demás y se proyecta a formar un país más equitativo para que se cristalice el cultivo de relaciones bajo parámetros similares, pero ubicando a la madre tierra como punto de partida para la convivencia armónica y la continuidad del Sumak Kawsay.

\section{DESAFÍOS Y UN ENCUENTRO CON NOSOTROS MISMOS}

En definitiva, el Sumak Kawsay tiene varias características, desde la prioridad de la naturaleza para vivir en armonía; el pensamiento de la cosmovisión como vida en comunidad, dejando todo tipo de individualismo para más bien pensar en conjunto; la importancia de cultivar relaciones -y una de las principales es la relación con la naturaleza sin apropiarse de ella-; y, finalmente, la responsabilidad con uno mismo, que es una forma de vivir bajo los lineamientos de complementación y reciprocidad. Así, la concepción del pensamiento ancestral alcanza la plenitud por lo que:

El Buen Vivir no es posible en una sociedad capitalista. Por eso, esta idea es el gran desafío que guía un necesario proceso de transición hacia la nueva sociedad que se anhela: una sociedad igualitaria donde las lógicas depredadoras de acumulación del capital sean reemplazadas por nuevas formas de producir, de consumir y de relacionarnos con la naturaleza. (Larrea, 2014, p. 30)

En este punto sobresale como ejemplo un aspecto fundamental enunciado por la autora Quirola en su artículo 'Sumak Kawsay. Hacia un nuevo pacto social en armonía con la naturaleza', publicado en el 2009 en el libro intitulado El Buen Vivir. Una vía para el desarrollo, en el que hace referencia a un llamado en el cual todos estamos involucrados, porque al ser conocedores del llamado de la comunidad Achuar de la selva amazónica ecuatoriana, indica que es necesario que "la sociedad despierte del letargo y con conciencia acoja la esperanza para trabajar juntos, dándole significado al Buen Vivir, pensando como un proceso social en armonía con la naturaleza" (Quirola, 2009, p. 40).

Así pues, si se acepta implícitamente el paradigma antes expuesto, el Sumak Kawsay debería entenderse como un reencuentro con nosotros mismos, que además de registrarse como un mandato constitucional en Ecuador, abre un abanico de oportunidades que han sido incorporadas en la Constitución de 
ese país y hacen hincapié en instituirse como un gran desafío direccionado a la no acumulación de riqueza como manera de vivir bien. El Sumak Kawsay tiene un enfoque que prioriza el concepto de compartir y pensar en todos; en otras palabras, apunta como meta principal, al vivir en armonía con nosotros mismos, con la naturaleza y con los demás. El pensamiento en comunidad, base sustancial del Sumak Kawsay, hace eco de esa cosmovisión que, si se adopta, debería formar parte de un cambio de ideología en el cual prime el bienestar justo de todos y no solo de unos pocos que olvidan las raíces ancestrales, eso permitiría alcanzar el "Buen Vivir".

\section{CONCLUSIONES}

El "Buen Vivir" responde a un cambio de vida profundo que ha sido incluido en la Constitución ecuatoriana como la búsqueda de una manera de salvaguardar la visión ancestral y posicionarla firme en el accionar de la sociedad actual. Y aunque en nuestro país el enfoque del Sumak Kawsay ha avanzado diligentemente, es necesario fortalecer su visión de respeto a los derechos de la naturaleza en conexión con el accionar del hombre.

Inequívocamente, la visión indígena deja un legado primordial: la armonía entre la sociedad y la naturaleza, todo esto encaminado a persistir en el progreso del país. No solo se trata de una visión sino de una forma diferente de compaginación de la vida con el compromiso de cuidar a la naturaleza. No se trata de una simple incorporación en la Carta Magna del Estado, sino de, en la práctica, valorar la vida con un enfoque en el cual todos seamos respetuosos con nosotros mismos, con la naturaleza y con los demás, para construir una sociedad más equitativa en la que nuestros derechos sean respetados y se logre la igualdad en la sociedad.

El "Buen Vivir" como un proyecto de desarrollo del socialismo supone una mejora en la calidad de vida de sus habitantes por sobre el capitalismo, es como se elevó a grado de obligatoriedad constitucional. Más que ser un encauce, nos deja la enseñanza muy importante respecto de que nuestros antepasados contemplaron el poder consolidar una sola fuerza para vivir en armonía en comunidad con la naturaleza.

La edificación de esta forma de vida implica nuestra acción directa porque no existe un camino concreto que direccione hacia esta forma de vida, si no es bajo nuestros propios parámetros de responsabilidad y respeto a la naturaleza en un accionar conjunto de toda la comunidad, que da paso a continuar en la construcción para beneficio de toda la sociedad ecuatoriana. 
El poner en práctica este nuevo enfoque de vida, que ya tenían los ancestros, es el paso firme hacia la construcción de un camino sólido que piensa en las generaciones presentes y en las que vendrán, para dejarles el legado de una cosmovisión de la cual todos debemos ser partícipes. Hoy, la tarea sería enfocarnos en cohabitar en un lugar fortalecido en una estrecha relación de respeto con la naturaleza y con los demás, dejando de lado el pensamiento individualista por uno que piensa en la comunidad. Todos somos artífices de este desafío que nos propone encontrarnos con nosotros mismos.

La línea jurisprudencial de la Corte Constitucional del Ecuador ha evolucionado al consagrar la noción de Sumak Kawsay. Si bien en un principio sus sentencias no brindaron una definición del "Buen Vivir", estas sí analizaron su fundamento y la concibieron como una verdadera forma de vida. Luego, la Sentencia N ${ }^{\circ}$ 166-15-SEP-CC de la Corte Constitucional del Ecuador, estableció al Sumak Kawsay como uno de los objetivos fundamentales del Estado ecuatoriano, considerando que tiene un valioso rol, al promocionar el desarrollo social y económico en armonía con la naturaleza.

Para finalizar, cabe insistir en que el pensamiento en comunidad, que es el principal sustento del Sumak Kawsay, implica un cambio de tendencia en el cual tenga prioridad un bienestar justo para todos y no solo de unos pocos que olvidan sus raíces ancestrales. Solo así se lograría el anhelado "Buen Vivir" en hechos, más allá de la palabra escrita.

\section{REFERENCIAS BIBLIOGRÁFICAS}

Acosta, A. (2009). Buen vivir Sumak Kawsay. Una oportunidad para imaginar otros mundos. Quito, Ecuador: Ediciones Abya-Yala.

Calapucha, C. (2012). Los modelos de desarrollo. Su repercusión en las prácticas culturales de construcción y del manejo del espacio en la cultura Kichwa Amazónica. Un análisis comparativo del desarrollo lineal en relación con el Sumak Kawsay. Cuenca, Ecuador: Universidad de Cuenca.

García, S. (2016). Sumak Kawsay o Buen Vivir como alternativa al desarrollo en Ecuador. Aplicación y resultados en el Gobierno de Rafael Correa (2007-2014). Quito, Ecuador: Universidad Andina Simón Bolívar. Ediciones Abya-Yala.

Guadynas, E. (2014). Buen Vivir: sobre secuestros, domesticaciones, rescates y alternativas En: A. Oviendo, Bifurcación del Buen Vivir y el Sumak Kawsay (pp. 25-44). Quito, Ecuador: Ediciones Sumak.

Hidalgo, A. \& Cubillo, A. (2014). Seis debates abiertos Buen vivir: sobre secuestros, domesticaciones, rescates y alternativas. Íconos. Revista de Ciencias Sociales Facultad Latinoamericana de Ciencias Sociales-Sede Académica de Ecuador, 25-45. 
Huanacuni, F. (2010). Buen Vivir/Vivir Bien. Filosofía, políticas, estrategias y experiencias regionales andinas. Lima, Perú: Coordinadora Andina de Organizaciones Indígenas-CAOI.

Larrea, A. (2014). El Buen Vivir como alternativa civilizatoria. En G. Endara, coordinador, Post-crecimiento y Buen Vivir. Propuestas globales para la construcción de sociedades equitativas y sustentables (pp. 239-256). Quito, Ecuador: Friedrich-Ebert-Stiftung (FES-ILDIS).

León, M. (2010). El 'buen vivir': objetivo y camino para otro modelo. En I. León, Sumak Kawsay/Buen Vivir y cambios civilizatorios (pp. 105-123), 2da edición. Quito, Ecuador: FEDAEPS.

Maldonado, L. (2010). Interculturalidad y políticas públicas en el marco del 'Buen Vivir'. En G. Fernández-Juárez, editor, Salud, interculturalidad y derechos. Claves para la reconstrucción del Sumak Kawsay-Buen Vivir (pp. 81-89). Quito, Ecuador: Ediciones Abya-Yala.

Maldonado, A. (2013). Un indicador para el Sumak Kawsay. Quito, Ecuador: Clínica Ambiental.

Oviendo, A. (2016). Qué es el sumak kawsay. Más allá del antropocentrismo de derecha e izquierda. Quito, Ecuador: Sumak Editores.

Palacios, F. (2008). Constitucionalización de un sistema integral de derechos sociales. De la Daseinsvorsorge al Sumak Kawsay. En R. Ávila Santamaría, A. Grijalva Jiménez y R. Martínez Dalmau, editores, Desafíos constitucionales. La Constitución ecuatoriana del 2008 en perspectiva (pp. 41-45). Quito, Ecuador: Ministerio de Justicia y Derechos Humanos.

Quintero, R. (2009). Las innovaciones conceptuales de la Constitución de 2008 y el Sumak Kawsay. En A. Acosta y E. Martínez, compiladores, El Buen Vivir. Una vía para el desarrollo (pp. 75-91). Quito, Ecuador: Ediciones Abya-Yala.

Quirola, D. (2009). Sumak Kawsay. Hacia un nuevo pacto social en armonía con la naturaleza. En A. Acosta y E. Martínez, compiladores, El Buen Vivir. Una vía para el desarrollo (pp. 103-114). Quito, Ecuador: Ediciones Abya-Yala.

Secretaría Nacional de Planificación y Desarrollo-Senplades (2009). Plan Nacional para el Buen Vivir 2009-2013: Construyendo un Estado Plurinacional e Intercultural. Quito, Ecuador: Consejo Nacional de Planificación.

Secretaría Nacional de Planificación y Desarrollo-Senplades (2013). Plan Nacional para el Buen Vivir 2013-2017: Todo el mundo mejor. Quito, Ecuador: Consejo Nacional de Planificación.

Secretaría Nacional de Planificación y Desarrollo-Senplades (2017). Plan Nacional para el Buen Vivir 2017-2021: Todo el mundo mejor. Quito, Ecuador: Consejo Nacional de Planificación.

Wilhelmi, M. (2008). Derechos: enunciación y principios de aplicación. En R. Ávila Santamaría, A. Grijalva Jiménez y R. Martínez Dalmau, editores, Desafíos constitucionales. La Constitución ecuatoriana del 2008 en perspectiva (pp. 19-39). Quito, Ecuador: Ministerio de Justicia y Derechos Humanos. 
Wray, N. (2009). Los retos del régimen de desarrollo. El Buen Vivir en la Constitución. En A. Acosta y E. Martínez, compiladores. El Buen Vivir. Una vía para el desarrollo (pp. 51-62), Quito, Ecuador: Ediciones Abya-Yala.

\section{SENTENCIAS}

Corte Constitucional del Ecuador, Dictamen No 0006-09-DTI-CC, de 14 de mayo de 2009.

Corte Constitucional del Ecuador, Sentencia Nº006-10-SEE-CC, de 25 de marzo de 2010.

Corte Constitucional del Ecuador, Sentencia No 166-15-SEP-CC, de 20 de mayo de 2015. 